\title{
AVALIAÇÃO DA UTILIZAÇÃO DE PLANILHAS ELETRÔNICAS COMO FERRAMENTA DE APOIO AO ENSINO DE ENGENHARIA
}

David Coverdale Rangel Velasco, Instituto Federal do Espírito Santo, Campus

Cachoeiro de Itapemirim, davidc.r.v2014@ gmail.com, orcid.org/0000-0001-9800-9764

Saymon da Silva Almeida, Instituto Federal Fluminense, Campus Campos Centro, saymon.g.a@ hotmail.com, orcid.org/0000-0001-5661-4296

Thais Mendes Almeida, Universidade Estácio de Sá, Campus Campos dos Goytacazes, thaismendes2001@gmail.com, orcid.org/0000-0001-6461-2039

Cassiana Barreto Hygino Machado, Instituto Federal Fluminense Campus avançado São João da Barra, cassiana.h.machado@iff.edu.br, orcid.org/0000-0002-0126-4169

Resumo: O ensino de disciplinas com cálculos extensos e complexos tem sido um desafio, sobretudo no Ensino a Distância. Neste sentido, diversos educadores têm avaliado formas de otimizar o ensino, sobretudo nos últimos anos durante a pandemia da COVID; que forçou milhões de professores a migrarem para o ensino remoto. A utilização de planilhas eletrônicas, por exemplo, possui o potencial de gerar ganhos de qualidade e produtividade nas mais diversas áreas e níveis de ensino. Este trabalho busca avaliar a utilização deste recurso na engenharia mecânica ao automatizar ações já estudadas, como conversão de unidades, aplicação de fórmulas e focar na discussão dos novos conteúdos abordados na aula. A pesquisa foi aplicada em um grupo de 28 alunos, sendo 17 (60\%) a quantidade que respondeu o questionário. Por meio desta pesquisa foi possível observar uma boa adesão da ferramenta pelos alunos, sendo todas as respostas neutras ou positivas, com média de 4,65 em uma escala de 1 a 5. Acrescenta-se ainda que, embora a pesquisa fosse realizada por meio de aulas remotas, os alunos manifestaram interesse que este recurso continuasse a ser utilizado presencialmente. Assim, espera-se que a partir dos resultados satisfatórios obtidos nesta pesquisa, planilhas eletrônicas possam ser utilizadas por outros docentes em diferentes modalidades de ensino.

Palavras-chave: Planilhas eletrônicas, ensino à distância, engenharia.

\section{EVALUATION OF THE USE OF ELECTRONIC SPREADSHEETS AS A TOOL TO SUPPORT ENGINEERING TEACHING}

Abstract: The teaching of subjects with extensive and complex calculations has been a challenge, especially in Distance Learning. In this sense, several educators have been evaluating ways to optimize teaching, especially in recent years during the COVID pandemic; that forced millions of teachers to migrate to remote learning. The use of electronic spreadsheets, for example, has the potential to generate gains in quality and productivity in the most diverse areas and levels of education. This work seeks to evaluate the use of this resource in mechanical engineering by automating actions already studied, such as converting units, applying formulas and focusing on the discussion of the new contents covered in the class. The survey was applied to a group of 28 students, 17 (60\%) being the number who answered the questionnaire. Through this research, it was possible to observe a good adherence to the tool by the students, with all responses being neutral or positive, with an average of 4.65 on a scale of 1 to 5 . It is also added that, although the 
research was carried out through of remote classes, students expressed interest that this resource continued to be used in person, indicating that this approach is also welcome in other types of teaching.

Keywords: Spreadsheets, Distance learning, engineering.

\section{INTRODUÇÃO}

A tecnologia tem estado cada vez mais presente no cotidiano de todos, sobretudo na vida dos jovens. Isto impacta diretamente no desenvolvimento mental dos alunos, gerando um novo padrão cognitivo dos atuais, diferente dos indivíduos de décadas passadas. Neste sentido, é importante que as tecnologias de ensino acompanhem não só os avanços tecnológicos, mas também a mudança no padrão cognitivo dos alunos (PAULA, 2012; PRENSKY, 2009).

Muitos professores possuem dificuldades em se enquadrar às Tecnologias Digitais da Informação e Comunicação (TDICs). O Brasil, por exemplo, ainda tem suas raízes no modelo de ensino tradicional, com predominância e extrema dependência da combinação do lápis, papel, quadro e livro. Mesmo a tecnologia sendo defendida para ser incluída nas salas de aula, muitos docentes ainda se sentem intimidados e amedrontados em utilizá-la, especialmente quando há falta de capacitação no seu manuseio (MELO, 2017).

Com o advento da pandemia do vírus Sars-CoV-2, responsável pela COVID-19, na tentativa de se adaptar a este agente externo, os professores tiveram que alterar seus métodos, utilizando o ensino remoto, mas em geral com recursos inferiores (infraestrutura, equipamentos eletrônicos, qualificação, etc) aos que outrora já atuavam nesta modalidade (SANTOS; LIMA; SOUSA, 2020).

Os educadores, na maioria dos casos, tiveram que lecionar em suas próprias casas, sendo que muitos não possuíam locais apropriados nem ao menos para instalação de equipamentos como o tradicional quadro. A Mesa digitalizadora, por exemplo, é um equipamento no qual muitos destes não têm experiência de utilização, tão pouco treinamento, apresentam, na resolução de exercícios com cálculos extensos, o mesmo problema que os slides; limitação de espaço (QUINTAIROS, 2020).

Acrescenta-se ainda que as metodologias alternativas que adotam ferramentas computacionais (Matlab, Wolfram Alpha, Microsoft Excel, Octave, etc) têm ganhado maior visibilidade, especialmente na modalidade de Ensino a Distância (EaD), por possibilitar elevar as taxas de aprovação, estímulo e adequação (SASSANO et al., 2021). Contudo, sabe-se que a engenharia tem uma forte tendência tradicionalista no seu ensino, o que implica em uma barreira na adoção de novas ferramentas de ensino. O uso de novos métodos pode levar a exclusão dos paradigmas entre as disciplinas, redefinindo, ao mesmo tempo, a função, a formação e o aperfeiçoamento dos docentes. No entanto, observada esta necessidade, ainda são poucas as pesquisas sobre a modernização do processo de ensino e aprendizagem nos cursos de engenharia, embora as existentes tenham avaliações positivas (BARRETO, 2004; GOMES; BATISTA; FUSIANATO, 2021).

Diversos autores apontam que existe um potencial na utilização de planilhas eletrônicas em sala de aula, sendo a maior parte dos estudos com caráter qualitativo e sobre temas específicos (CÓSER FILHO, 2008; DO NASCIMENTO e ASSUNÇÃO, 2016; VELASCO et al., 2021a, 2021b).

Neste sentido, este trabalho se desenvolveu a partir da seguinte questão: como contribuir para a visualização dos fenômenos vinculados a cálculos considerados complexos, por parte dos professores da área de engenharia? No intuito de responder esta 
questão o seguinte objetivo foi proposto: avaliar a utilização de planilhas eletrônicas no Curso de Engenharia. Para alcançar este objetivo, foram realizados levantamentos na literatura sobre a utilização de tecnologias aplicadas ao ensino de engenharia, de modo especial a utilização das planilhas eletrônicas.

Para a avaliação das planilhas eletrônicas no ensino de engenharia, foram criadas planilhas referentes ao tema projeto e dimensionamento de sistemas de tubulações industriais, como também elaboradas e aplicadas aulas, tendo como público-alvo alunos do curso de Engenharia Mecânica. A premissa é que a utilização de planilhas eletrônicas na resolução de exercícios extensos implica em um ganho de produtividade e qualidade da aula, bem como auxiliam na preparação dos alunos na utilização desta ferramenta no mercado de trabalho.

\section{REFENCIAL TEÓRICO}

Acompanhando a evolução tecnológica mundial, as engenharias, que antes foram criadas para atender as necessidades bélicas, avançaram e se espalharam de tal forma que se integraram às diferentes áreas do conhecimento (RODRIGUES; ARANTES, 2020).

No Brasil, houve um grande investimento na área industrial, tanto em relação à expansão do maquinário, principalmente no investimento em máquinas atuantes nos processos de fabricação, quanto ao desenvolvimento do processo formativo dos indivíduos capazes de operar estas máquinas (MACEDO; SAPUNARU, 2016; MARSON, 2014).

A relação entre professores e alunos dos cursos de engenharia tem sofrido grandes mudanças, mas não tão rapidamente quanto às mudanças tecnológicas em nossa sociedade, pois no que se refere ao ensino, o professor ainda é visto como o detentor do conhecimento (CANDIDO et al. 2020).

Visando melhorar o ensino para a formação de engenheiros, o Instituto Tecnológico de Aeronáutica (ITA) lançou em 2016 um projeto de modernização do ensino na engenharia. Uma das metas estabelecidas seria de adotar uma pedagogia multidisciplinar e interdisciplinar. Essa meta ajudaria a atender as novas necessidades que um engenheiro precisa para entrar no mercado de trabalho, deixando de ser aulas somente receptivas de conhecimentos, adotando as tecnologias, modernidade e uma educação mais ativa (ITA, 2016).

A utilização de planilhas eletrônicas tem se destacado em diversas áreas e níveis de ensino, podendo ser utilizadas em salas de aula, práticas laboratoriais, pesquisas científicas. A literatura aponta que a maior parte das aplicações deste recurso, com finalidade didática, estão relacionadas a conteúdos com cálculos complexos e extensos, em cursos de nível médio e superior (CÓSER FILHO, 2008; DO NASCIMENTO e ASSUNÇÃO, 2016; VELASCO et al., 2021a, 2021b).

Uma planilha eletrônica, ou folha de cálculo, pode ser definida como um tipo de programa, que por meio de uma representação matricial, possibilita a realização de cálculos e/ou a apresentação de dados. Acrescenta-se ainda, que ao adicionar programação, este recurso torna-se um dos mais potentes disponíveis para a sociedade em geral, podendo ser utilizado para as mais diversas aplicações (DIAS, 2013; JELEN, 2017).

Segundo Almeida et al. (2020), mesmo que a utilização de aplicativos em salas de aula possa resultar em ganho de produtividade e facilitar o ensino, dificilmente um aplicativo atenderá a todas as demandas de um professor. Diferentemente da maioria dos aplicativos, os programas de planilhas eletrônicas permitem um maior leque de possibilidades, proporcionando ao professor criar e personalizar a planilha com mais 
flexibilidade, podendo esta ser utilizada em diversos tipos de dispositivos por meio de diferentes softwares (VELASCO et al., 2021a).

$\mathrm{Na}$ engenharia, até mesmo livros clássicos como o "Tubulações industriais: Cálculo" de Telles (1999), apresentam soluções extensas por meio de planilhas eletrônicas, visto a simplicidade de interpretação dos resultados. Na resolução destes exercícios em sala de aula, a utilização de planilhas eletrônicas permite soluções interativas, estas possibilitam alterar valores uma célula e por consequência observar os efeitos de diferentes escolhas no resultado de um projeto (BREWER; BAREISS, 2016; SANTOS; NUNES, 2013).

As pesquisas sobre as planilhas no ensino de engenharia apontam a sua importância na formação dos alunos. Ferreira e Vieira (2017), fazendo um diagnóstico a respeito do uso de software nos cursos de Engenharia Química, em diversas universidades públicas e privadas no Brasil, concluíram que o Excel é o mais utilizado, possivelmente devido ao fato de sua ampla capacidade e versatilidade ao auxiliar em diversos problemas, de modo interativo (solução passo a passo).

Sassano e colaboradores (2021) estudaram a utilização de diversas ferramentas computacionais em disciplinas com cálculos complexos e/ou extensos que pertencem ao ciclo básico da engenharia. Em sua pesquisa o Microsoft Excel se destacou como a ferramenta que obteve o melhor desempenho em geral, sendo em algumas disciplinas a utilização do MatLab ou Scilab melhores avaliadas. Estes programas possibilitam obter soluções por meio de desenvolvimento de algoritmos, o que no Excel só seria possível com a utilização do Visual Basic for Applications (VBA), recurso que não foi avaliado no trabalho supracitado.

Niazkar e Afzali (2015) analisaram atividades feitas por diversos alunos de conteúdos específicos de diferentes áreas na engenharia, e concluíram que a planilha é uma ferramenta que possui grande potencial, pois a análise das atividades feitas pelos alunos, não importando a área de engenharia, indicou otimização das aulas.

\section{METODOLOGIA}

A metodologia deste trabalho é qualitativa, visto que a proposta deste trabalho é realizar uma pesquisa de forma a avaliar a utilização de planilhas eletrônicas sem caráter estático, mas sim visando validar a utilização de uma tecnologia numa aplicação específica (GERHARDT; SILVEIRA, 2009).

A pesquisa foi realizada com 28 alunos da disciplina de Tubulações Industriais do curso de Engenharia Mecânica, no segundo semestre de 2020. Antes da aplicação das aulas, as planilhas foram desenvolvidas pelos autores, por meio do Microsoft Excel, cf. Telles, 1999, para o dimensionamento e seleção de tubulações. Contudo, os alunos não ficaram restritos a utilizar apenas este software para solução dos problemas, visto que o formato no qual as planilhas foram disponibilizadas era compatível com outros programas como o Calc Libre Office e o Google Sheets, que são softwares gratuitos. Vale ressaltar que os alunos já tinham estudado o Microsoft Excel anteriormente, em outra disciplina.

As planilhas foram elaboradas de forma que os alunos continuassem tendo que tomar todas as decisões de projeto, bem como fornecer informações provenientes de ábacos e normas. Contudo, a conversão de unidades, aplicação de fórmulas anteriormente apresentadas e realização de interpolações foram realizadas com o auxílio da planilha eletrônica. Acrescenta-se ainda, que embora desenvolvidas para utilização em sala de aula, as planilhas construídas com os alunos estão de acordo com a normalização técnica vigente e, portanto, posteriormente podem ser utilizadas no ambiente profissional pelos futuros engenheiros. 
Após o fim do semestre letivo, foi realizada uma pesquisa anônima do tipo Survey exploratória ${ }^{1}$ em escala de Likert $^{2}$ com 5 pontos por meio do Google Forms. As assertivas utilizadas foram baseadas na pesquisa por Dania e Posey (2012) e adaptadas a especificidades desta pesquisa, havendo assertivas positivas e negativas em relação a utilização de planilhas eletrônicas. Posteriormente, a escala de Likert foi convertida em notas de uma escala de 1 a 5 . Nas assertivas positivas, que se encontram presentes na Tabela 1 com sombreamento azul, foi atribuída uma nota 5 para concordo plenamente, 4 para concordo, 3 para neutro, 2 para discordo e 1 para discordo plenamente.

Nas assertivas negativas, que se encontram na Tabela 1 em sombreamento vermelho, foi seguida a lógica contrária. As notas atribuídas foram invertidas. Assim, foi atribuído 1 para concordo plenamente, 2 para concordo, 3 para neutro, 4 para discordo e 5 para discordo plenamente.

A mistura de assertivas positivas e negativas foi observada no trabalho de referência Dania e Posey (2012) e foi mantida neste trabalho por favorecer a veracidade das respostas individuais de cada assertiva, observando e impedindo aqueles que estivessem respondendo sempre a mesma alternativa sem ao menos ler o todo. Por fim, ao terminar de avaliar as assertivas, o aluno teve a opção de tecer um comentário acerca da disciplina.

\section{RESULTADOS E DISCUSSÃO}

Em virtude da limitação de espaço, a Figura 1 apresenta apenas uma parte da planilha desenvolvida, sendo esta responsável pelo cálculo da espessura necessária de uma tubulação. Nesta imagem é possível observar que a planilha permite tanto agilizar os cálculos e observar os mesmos na região a direita, com sombreamento roxo, como também de forma resumida apresentar uma especificação da tubulação avaliada.

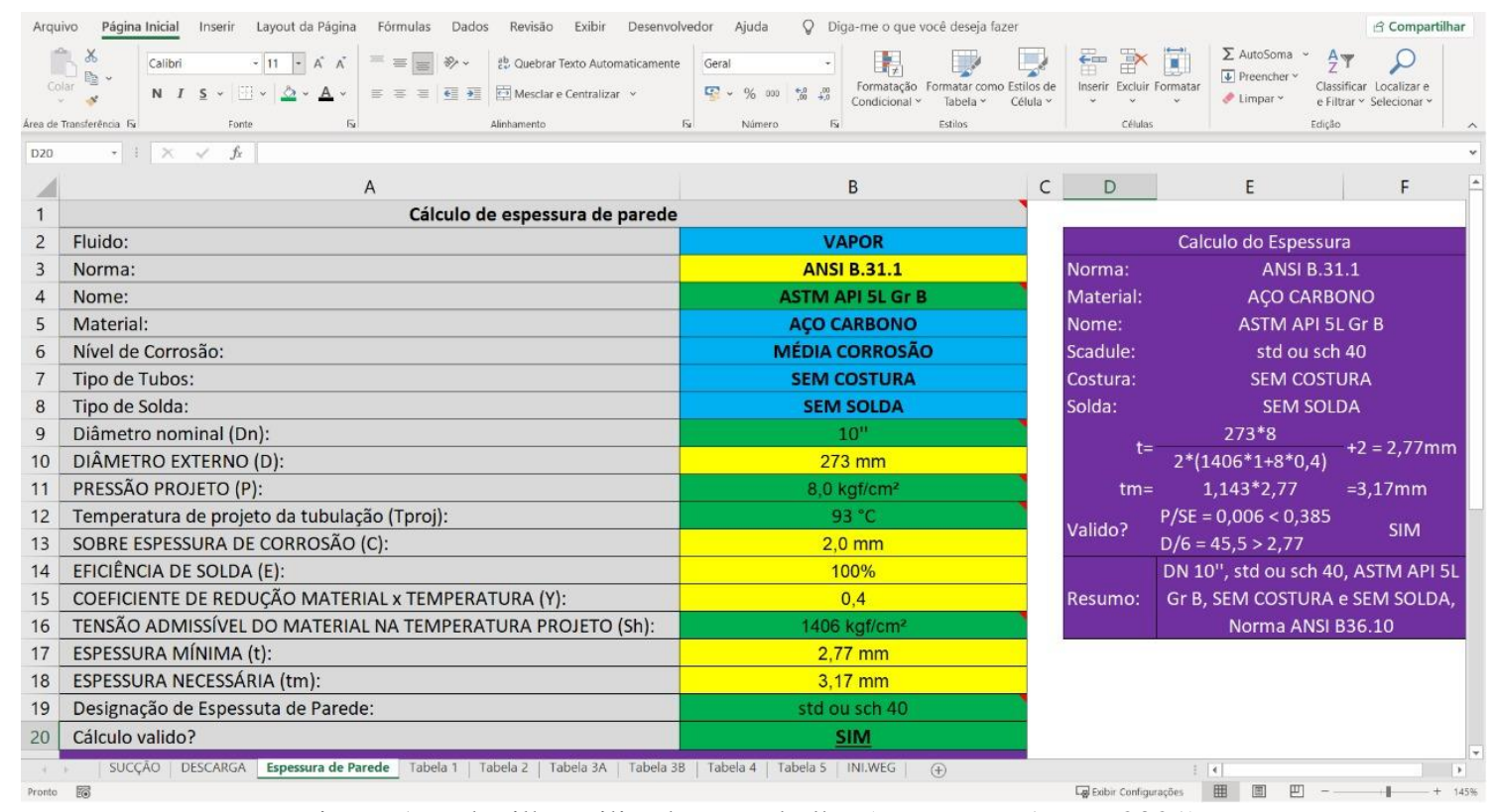

Figura 1 - Planilha utilizada no trabalho (Fonte: Do Autor, 2021).

Esta parte da planilha, por exemplo, é possível que o aluno troque algumas variáveis como o material, tipo de tubulação ou fluido e que rapidamente seja demonstrada a influência destas variáveis no projeto e seleção de tubulações. Isto possibilita que sejam discutidas rapidamente as ideias de alunos que sejam diferentes da solução do professor, demonstre na prática como seria impactado um projeto por V. $19 \mathrm{~N}^{\circ}$ 2, Dezembro, 2021 RENOTE 
diferentes decisões em sua elaboração, o que implica em uma aula com maior produtividade e interação, como esperado segundo a literatura (BREWER; BAREISS, 2016; SANTOS; NUNES, 2013).

Dos 28 alunos consultados, 17 responderam à pesquisa, aproximadamente $60 \%$ dos participantes da pesquisa, sendo na Tabela 1 apresentada a quantidade de respostas obtidas e a nota média por assertiva. Por meio desta foi possível observar uma boa avaliação geral dos alunos, sendo a média geral 4,65 em uma escala de 1 a 5. Acrescentase ainda que não foi observada nenhuma avaliação negativa acerca da utilização desta ferramenta, sendo unânime entre os alunos que a utilização de planilhas eletrônicas auxilia de certa forma o aprendizado. O quantitativo de respostas recebidas é aproximadamente igual ao observado no trabalho de Dania e Posey (2012), sendo que neste trabalho, a aplicação foi melhor avaliada.

Tabela 1: Quantidade de respostas (por nota) e nota média por assertiva.

\begin{tabular}{|c|c|c|c|c|c|c|}
\hline Assertivas & $\begin{array}{l}\text { Nota } \\
5\end{array}$ & $\begin{array}{c}\text { Nota } \\
4\end{array}$ & $\begin{array}{c}\text { Nota } \\
3\end{array}$ & $\begin{array}{c}\text { Nota } \\
2\end{array}$ & $\begin{array}{c}\text { Nota } \\
1\end{array}$ & $\begin{array}{l}\text { Nota } \\
\text { Média }\end{array}$ \\
\hline $\begin{array}{l}1^{\text {a })} \text { O texto das planilhas eletrônicas na tela é grande o } \\
\text { suficiente para ser lido (quando em apresentação pelo } \\
\text { instrutor). }\end{array}$ & 15 & 0 & 2 & 0 & 0 & 4,76 \\
\hline $\begin{array}{l}2^{\text {a }) ~ U t i l i z a c ̧ a ̃ o ~ d e ~ p l a n i l h a s ~ e l e t r o ̂ n i c a s ~ a d i c i o n a m ~} \\
\text { interesse ao conteúdo apresentado. }\end{array}$ & 15 & 0 & 2 & 0 & 0 & 4,76 \\
\hline $\begin{array}{l}3^{\text {a }) ~ A ~ u t i l i z a c ̧ a ̃ o ~ d o ~ p l a n i l h a s ~ e l e t r o ̂ n i c a s ~ p a r a ~ r e s o l v e r ~} \\
\text { exercícios auxiliou no processo de aprendizagem. }\end{array}$ & 15 & 2 & 0 & 0 & 0 & 4,88 \\
\hline $\begin{array}{l}4^{a} \text { ) A utilização de planilhas eletrônicas ajudou a focar } \\
\text { nos pontos mais relevantes do conteúdo ministrado. }\end{array}$ & 15 & 0 & 2 & 0 & 0 & 4,76 \\
\hline $\begin{array}{l}5^{\text {a) }} \text { Sinto que não preciso consultar repetidas vezes o } \\
\text { material de apoio e/ou bibliografia ao utilizar as } \\
\text { planilhas eletrônicas. }\end{array}$ & 5 & 12 & 0 & 0 & 0 & 4,29 \\
\hline $\begin{array}{l}\left.6^{a}\right) \text { O ritmo da aula ao usar planilhas eletrônicas é mais } \\
\text { rápido do que quando usando apenas o quadro-negro. }\end{array}$ & 15 & 0 & 2 & 0 & 0 & 4,76 \\
\hline $\begin{array}{l}7^{\text {a) }} \text { Ser capaz de revisar as soluções da planilha } \\
\text { eletrônica depois da aula me ajuda a reforçar minha } \\
\text { compreensão da mesma. }\end{array}$ & 12 & 5 & 0 & 0 & 0 & 4,71 \\
\hline $\begin{array}{l}8^{\text {a }) ~ A ~ u t i l i z a c ̧ a ̃ o ~ d e ~ p l a n i l h a s ~ e l e t r o ̂ n i c a s ~ e s t a ́ ~ m e ~} \\
\text { ajudando a obter uma nota melhor. }\end{array}$ & 17 & 0 & 0 & 0 & 0 & 5,00 \\
\hline $\begin{array}{l}\left.9^{a}\right) \text { Eu preferiria que o instrutor usasse o quadro-negro, } \\
\text { em vez do que de planilhas eletrônicas. }\end{array}$ & 8 & 9 & 0 & 0 & 0 & 4,47 \\
\hline $\begin{array}{l}\left.10^{a}\right) \text { A forma como as planilhas eletrônicas são usadas } \\
\text { na aula ajuda na discussão sobre a mesma. }\end{array}$ & 8 & 8 & 1 & 0 & 0 & 4,41 \\
\hline $\begin{array}{l}\text { 11 a) A utilização de planilhas eletrônicas prejudica na } \\
\text { interação entre alunos e instrutor. }\end{array}$ & 8 & 9 & 0 & 0 & 0 & 4,47 \\
\hline $\begin{array}{l}\left.12^{a}\right) O \text { instrutor equilibra a utilização de planilhas } \\
\text { eletrônicas com outras classes de atividades. }\end{array}$ & 8 & 9 & 0 & 0 & 0 & 4,47 \\
\hline $\begin{array}{l}13^{\text {a }} \text { ) A forma que as planilhas eletrônicas foram } \\
\text { desenvolvidas está de acordo com o conteúdo } \\
\text { ministrado. }\end{array}$ & 14 & 3 & 0 & 0 & 0 & 4,82 \\
\hline $\begin{array}{l}\left.14^{\mathrm{a}}\right) \text { Considerando todas as coisas, eu consideraria a } \\
\text { planilha eletrônica um fator positivo na aula. }\end{array}$ & 12 & 5 & 0 & 0 & 0 & 4,71 \\
\hline
\end{tabular}




\begin{tabular}{|c|c|c|c|c|c|c|}
\hline Assertivas & $\begin{array}{c}\text { Nota } \\
5\end{array}$ & $\begin{array}{c}\text { Nota } \\
4\end{array}$ & $\begin{array}{c}\text { Nota } \\
3\end{array}$ & $\begin{array}{c}\text { Nota } \\
2\end{array}$ & $\begin{array}{c}\text { Nota } \\
1\end{array}$ & $\begin{array}{l}\text { Nota } \\
\text { Média }\end{array}$ \\
\hline 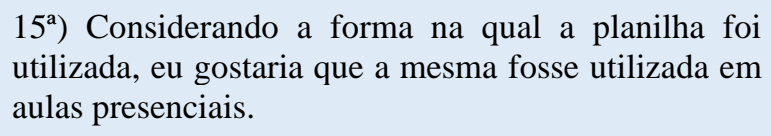 & 10 & 7 & 0 & 0 & 0 & 4,59 \\
\hline $\begin{array}{l}16^{\mathrm{a}} \text { ) A utilização de planilhas eletrônicas contribuiu } \\
\text { para que eu utilize melhor a mesma em ambientes } \\
\text { profissionais. }\end{array}$ & 10 & 7 & 0 & 0 & 0 & 4,59 \\
\hline \multicolumn{6}{|c|}{ Média geral } & 4,65 \\
\hline
\end{tabular}

A assertiva com menor avaliação foi a quinta $\left(5^{\mathrm{a}}\right)$, onde o valor médio obtido foi 4,29 , o que indica que mesmo sendo a menor avaliação, ela foi positiva. Esta avaliação indica que embora a planilha eletrônica tenda a reduzir a tendência de consultar repetidas vezes o material didático, os mesmos são necessários para complementar as informações que não estão presentes dentro da planilha.

De acordo com as assertivas que alcançaram maiores avaliações, que se encontram acima da média geral, estão: $1^{\mathrm{a}}, 2^{\mathrm{a}}, 3^{\mathrm{a}}, 4^{\mathrm{a}}, 6^{\mathrm{a}}, 7^{\mathrm{a}}, 8^{\mathrm{a}}, 13^{\mathrm{a}}$ e $14^{\mathrm{a}}$. Ao observar a $1^{\mathrm{a}}$ e $3^{\mathrm{a}}$ assertiva percebeu-se que não há praticamente incompatibilidade em modo apresentação pelo professor, podendo ser utilizadas para a resolução de exercícios, ajudando no processo de ensino e aprendizagem. Nas assertivas $4^{\mathrm{a}}$ e $6^{\mathrm{a}}$, observou-se que com a utilização das planilhas há uma otimização do tempo de aula, em comparação à utilização exclusivamente do quadro, permitindo os alunos se atentarem no que realmente é importante neste conteúdo. Já na $2^{\mathrm{a}}, 13^{\mathrm{a}}$ e $14^{\mathrm{a}}$ é possível perceber que o modo na qual foram desenvolvidas as planilhas resultou em uma interação homem-computador que permitiu que fosse aguçado o interesse pelo conteúdo, gerando assim considerações positivas. As ideias expressas nas assertivas $7^{\mathrm{a}}$ e $8^{\mathrm{a}}$, mostram que as planilhas podem ser utilizadas fora do ambiente escolar como um reforço, ajudando os alunos no seu percurso acadêmico.

Entre as assertivas, a $3^{\mathrm{a}}$ e $8^{\mathrm{a}}$ se destacam por sua elevada avaliação, indicando que a utilização de planilhas eletrônicas auxilia não só a obtenção de notas melhores, mas também auxiliou no processo de aprendizagem. Isto é ressaltado pelos Alunos 17 e 12, que teceram os seguintes comentários: "Um benefício da utilização do Excel é que ele realizava contas simples e repetitivas como conversão de unidades, enquanto permitia focar mais no conteúdo novo que estava sendo apresentado", "Usar o excel ajudou muito no aprendizado, queria que fosse utilizado por outros professores". O que também foi observado na pesquisa de Niazkar e Afzali (2015), onde percebeu-se uma otimização das aulas.

Acrescenta-se ainda, que outro aluno destacou que a mesma importância que as planilhas utilizadas dentro de sala de aula tem, também pode ter de fora dela. O Aluno 8 disse: "Muito bom esse método, principalmente por ter como ficar testando mudar algumas coisas fora da aula e ver o resultado". Esta interatividade que o aluno ressaltou é uma das principais razões pela qual as planilhas eletrônicas são utilizadas, sendo também ressaltada por Ferreira e Vieira (2017).

Nos comentários dos Alunos 6 e 10, respectivamente, é possível observar a importância de trabalhos similares no incentivo ao despertar do interesse dos alunos pelo conhecimento das planilhas eletrônicas, "O melhor para mim foi que durante a aula me interessei por uma ferramenta que não conhecia", "Muito legal esse jeito de dar aula". O Excel é a principal plataforma de desenvolvimento de planilhas eletrônicas da atualidade, mas estima-se que um usuário intermediário não sabe nem $10 \%$ de seus recursos, assim 
a utilização deste recurso em aula tende a ampliar o leque de ferramentas, sendo estas aplicadas a realidade do futuro trabalho do aluno (JELEN, 2017; VELASCO et al. 2021a).

Por fim, outros alunos destacaram, por meio de seus comentários, como a utilização de planilhas eletrônicas pode ser interessante, não só pelos benefícios agregados a aula, mas também por ser uma ferramenta muitas das vezes utilizada por engenheiros: Aluno 5, "Utilizar o Excel foi bom para praticar algo que não usava a mto tempo", e o Aluno 1, "Queria que mais vezes fosse utilizada uma ferramenta como essa em sala de aula, pois além ajudar na qualidade da aula, ajuda a nos acostumarmos com uma ferramenta de trabalho". Isto indica que a utilização desta ferramenta é importante para o desenvolvimento de um engenheiro da atualidade e pode colaborar para atingir metas como as estabelecidas pelo ITA (2016).

\section{CONCLUSÕES}

O objetivo deste trabalho é avaliar se a utilização de planilhas eletrônicas em disciplinas de engenharia, especial as que contém cálculos complexos, é benéfica para as aulas. Visto que não foi reportada nenhuma avaliação negativa, tanto nas opiniões expressas pelos alunos, em forma de comentários, como em quaisquer das assertivas apresentadas, mas pelo contrário, foi observada uma avaliação média de 4,65 em uma escala de 1 a 5, pode-se assim observar a efetividade das planilhas eletrônicas para a aplicação avaliada.

Contudo, assim como outras tecnologias, recomenda-se que para a utilização das planilhas eletrônicas haja uma qualificação prévia do professor, bem como, que os alunos tenham o mínimo de conhecimento sobre o manuseio desta ferramenta. Deste modo, os resultados obtidos foram frutos de uma aplicação nestas condições, justificando-se apresentar um desempenho superior do observado em outras literaturas.

Acrescenta-se ainda, que embora a aplicação desta ferramenta tenha sido avaliada em uma modalidade $\mathrm{EaD}$, todos afirmaram que gostariam de que a utilização de planilhas também fosse realizada no ensino presencial.

\footnotetext{
${ }^{1}$ Um dos principais métodos de pesquisa exploratória, meio de coleta de dados a partir das opiniões dos indivíduos que tem como objetivo não construir uma resposta definitiva, mas sim elaborar hipóteses (GIL; REIS NETO, 2021).

${ }^{2}$ Escala em que é possível analisar o grau de concordância ou discordância de determinadas afirmações (assertivas) previamente feitas (MALHOTRA, 2001). Embora seja um instrumento estatístico, neste presente artigo foi utilizado sem finalidade quantitativa, tendo como principal objetivo reunir várias opiniões padronizadas para posterior análise.
}

\section{REFERÊNCIAS}

ALMEIDA, S. S.; MARCELINO, V. S.; MACHADO, C. M. B. H. Ensino de Química e Aplicativos Educacionais: elaboração de material didático. Revista EducaOnline, v. 14, p. $98-114,2020$.

BARRETO, R. G. Tecnologia e educação: trabalho e formação docente. Educação \& Sociedade, v. 25, p. 1181-1201, 2004.

BREWER, K.; BAREISS, C. Iterative Solutions. In: (Eds.). Concise Guide to Computing Foundations. Cham: Springer International Publishing, p. 65-81,2016. 
CANDIDO, J.; BARRETO, G.; CAMARGO, J. T. F.; VERASZTO, E. V. (2020). O porquê da necessidade de se investir em um programa de formação docente nos cursos das engenharias no Brasil. Revista de Ensino de Engenharia, p. 129, 2020.

CÓSER FILHO, M. S. Aprendizagem de Matemática financeira no ensino médio: uma proposta de trabalho a partir de planilhas eletrônicas. Dissertação - Porto Alegre: Universidade Federal do Rio Grande do Sul, 2008.

DANIA, A.; POSEY, C. Accounting Students Opinions towards use of Spreadsheets as an Instructional Tool. Journal of Business, v. 17, p. 15, 2012.

DIAS, F. F. O uso da planilha eletrônica Calc no ensino de matemática no primeiro ano do ensino médio, 2013.

DO NASCIMENTO, H. L. F.; ASSUNÇÃO, R. M. O uso de planilhas eletrônicas no auxílio do ensino da Contabilidade nos cursos técnicos do Campus Ifam-Itacoatiara-AM. Revista Brasileira de Contabilidade, v. 219, p. 74-81, 2016.

FERREIRA, M. C.; VIEIRA, F. T. Diagnóstico do uso de softwares computacionais no ensino de Engenharia Química. Blucher Chemical Engineering Proceedings, v. 4, n. 1, p. 81-84, 2017.

GERHARDT, T. E.; SILVEIRA, D. T. (EDS.). Métodos de pesquisa. Porto Alegre: Editora da UFRGS, 2009.

GIL, A. C.; CRESPO, A. Survey de Experiência como Pesquisa Qualitativa Básica em Administração. Revista de Ciências da Administração (CAD/UFSC), v. 22, p. 125-137, 2021.

GOMES, E. C.; BATISTA, M. C.; FUSINATO, P. A. The use of active methodologies in engineering courses in brazil from thesis and dissertations. Revista Valore, n. 6, p. 471-483, 2021.

ITA. Realizações 2016. Instituto Tecnológico de Aeronáutica, p.14-15, 2016. Disponível em: <https://issuu.com/itaexpansao/docs/ita_relatorio2016_20170510>. Acesso: 17 set. 2021.

JELEN, B. Excel 2016: VBA e Macros. Alta Books Editora, 2017.

LABARCA, G. ¿Cuánto se puede gastar en educación? Revista de la CEPAL, n. 56, p. 163-178, ago. 1995.

MACEDO, G.M.; SAPUNARU, R.A. Uma breve história da engenharia e seu ensino no Brasil e no mundo: foco Minas Gerais. Revista de Engenharia da Universidade Católica de Petrópolis, v. 10, n 1, p. 39-52, 2016.

MALHOTRA, N. K. Pesquisa de marketing: uma orientação aplicada. 3. ed. Porto Alegre: Bookman, 2001. 
MARSON, M. D. A evolução da indústria de máquinas e equipamentos no Brasil: Dedini e Romi, entre 1920 e 1960. Nova Economia, v. 24, n. 3, p. 686, 2014.

Melo, E.; Ferreira, R.; Araújo R.; Nunes, I. Problemas para a inserção das tecnologias digitais de comunicação e informação nas escolas públicas da grande natal: um levantamento entre professores de matemática. In: Anais dos Workshops do Congresso Brasileiro de Informática na Educação, 2017. p. 834.

NIAZKAR, M. e AFZALI, S. H. Application of Excel spreadsheet in engineering education. In: First International \& Fourth National Conference on Engineering Education, Shiraz University, p. 1-7, 2015.

PAULA, L. A. L. Jovens e Novas Formas de Cognição: algumas reflexões sobre a escola. In: ARANHA, G.; SHOLL-FRANCO, A. Caminhos da Neuroeducação. Rio de Janeiro: Ciências e Cognição, p. 9-22, 2012.

QUINTAIROS, P. C. R. Desafios para o ensino de física em aulas on-line: o uso de mesa digitalizadora e do whiteboard. Revista de Pesquisa Aplicada e Tecnologia (REPATEC), v. 2, p. 5, 2020.

RODRIGUES, A. V.; ARANTES, E. G. As tecnologias e o ensino de Engenharia: uma breve discussão. In: FRANCO, G.; DE OLIVEIRA, K. C.; PANTANO FILHO, R. (Org.). Educação, Ciência e Tecnologia. Salto: FoxTablet, p. 84-92, 2020.

SANTOS, A. C. F.; NUNES, L. N. Utilizando analogias para a visualização de equipotenciais com uma planilha de dados. Revista Brasileira de Ensino de Física, v. 35, n. 2, p. 1-9, jun. 2013.

SANTOS, E.; LIMA, I. S.; SOUSA, N. J. "Da Noite para o Dia" o Ensino Remoto: (re)invenções de professores durante a pandemia. Revista Brasileira de Pesquisa (Auto)Biográfica, v. 5, n. 16, p. 1632-1648, 2020.

SASSANO, F. C. N.; NETO, H. L. G.; BARIZÃO, A. H.; SENCIO, R. R.; ONAYA, Á.; WELTER, N. O uso de ferramentas computacionais no processo de ensino e aprendizagem de matemática na EAD. Revista Brasileira de Aprendizagem Aberta e a Distância, v. 20, n. 1, 18 maio 2021.

TELLES, P. C. S. Tubulações Industriais: Cálculo. 9. ed. Rio de Janeiro: Livros Técnicos e Científicos (LTC) Editora, 1999.

VELASCO, D. C. R.; Linhares Júnior, J. A. T.; Lopes, F. P. D.; Caetano, E. Desenvolvimento de uma planilha para calibração de manômetros uma forma simplificada de mensurar a incerteza da medição. Anais do VII CONEPE. In: VII Congresso de Pesquisa e Extensão. Campos dos Goytacazes: 2021a.

VELASCO, D. C. R.; Lôbo, E. T.; Santos, W. A.; Bretas, W. V.; Fernandes, R. M. Desenvolvimento de uma ferramenta computacional para dimensionamento e analise da viabilidade econômica de sistemas fotovoltaicos. Anais do VII CONEPE. In: VII Congresso de Pesquisa e Extensão. Campos dos Goytacazes: 2021b. 